\title{
Human Immunodeficiency Virus, Syphilis Prevalence and Risk Factors among Migrant Workers in Konongo, Ghana
}

\author{
Andrew A. Adjei ${ }^{1}$, James Brandful' ${ }^{2}$, Mark Lurie ${ }^{3}$, Margaret Lartey'1, Francis Krampa1, \\ Awewura Kwara ${ }^{3}$, Theophilus K. Adiku', Yao Tettey', Richard K. Gyasi', Aaron L. Lawson', \\ Timothy Flanigan ${ }^{3}$ \\ ${ }^{1}$ University of Ghana Medical School, College of Health Sciences, Accra, Ghana \\ ${ }^{2}$ Noguchi Memorial Institute for Medical Research, Legon, Ghana \\ ${ }^{3}$ Brown University School of Medicine, Rhode Island, USA \\ Email: andrewanthonyadjei@yahoo.com
}

Received 7 May 2014; revised 7 June 2014; accepted 30 June 2014

Copyright (C) 2014 by authors and Scientific Research Publishing Inc.

This work is licensed under the Creative Commons Attribution International License (CC BY). http://creativecommons.org/licenses/by/4.0/

(c) (i) Open Access

\begin{abstract}
Migrant workers, particularly gold mining workers, have been identified as a group at risk for HIV and sexually transmitted infections (STI). A cross-sectional study was undertaken on the correlates of human immunodeficiency virus (HIV) and syphilis infections in a sample of migrants (Ghanaian citizens [156] and non-Ghanaian citizens [8]) working in a gold mining centres in Konongo, Ghana. The study was conducted between the months of January 2013 to December 2013. Of a total of 600 eligible migrant workers, only 164 (27.33\%; males 114, females 50) of the eligible migrants took part in the study. Subjects voluntarily completed a risk-factor questionnaire and provided blood specimen for testing for the presence of antibodies to HIV and Treponema palli$d u m$, the causative agent of syphilis. These data were analyzed using both univariate and multivariate techniques. The median age of the participants was 29.0 years (range 18 - 62 years). Of the 164 migrant workers tested, HIV and syphilis seroprevalence were $6.7 \%$ and $3.7 \%$ respectively. On multivariate analysis, the independent determinants for HIV infection were being female [odds ratio (OR) 2.94; 95\% confidence interval (95\% CI 0.86 - 10.0); unmarried (OR 10.13; 95\% CI 1.2 81.09); drug use (OR 3.76; 95\% CI 0.38 - 36.3); and blood transfusion (OR 2.45; 95\% CI 0.27 22.37). Similarly, on multivariate analysis, the independent determinants for syphilis infection were having concurrent sexual partners (OR 2.16; 95\% CI 0.38 - 12.12); and blood transfusion (OR 5.07; 95\% CI 0.51 - 50.37). Consistent with similar studies worldwide, our results suggest high prevalence of HIV and syphilis infections among migrant workers who work in gold mining centres in Ghana.
\end{abstract}




\section{Keywords}

\section{HIV Seropositivity, Syphilis Seropositivity, Migrant Workers, Gold Mining Centres, Risk Factors}

\section{Introduction}

Human immunodeficiency virus (HIV) has now spread to all parts of the world and the rates of infection are found to be particularly high in those cities with a greater number of migrants [1] [2]. The relation between migration (long-term stay) and mobility (short-term stay), particularly of individuals and/or families from rural areas to cities for economic opportunity, and the high transmission of HIV/sexually transmitted infections (STIs) have been known for several years [2]-[5]. Studies from Africa and Asia have demonstrated a link between migration and multi-partner sexual networking as well as the prevalence of HIV/STIs [6]-[11]. Within these regions, there is growing evidence that the high rates of HIV/STIs among migrant men largely occur by sexual contact with HIV/STIs-infected women, often sex workers, while away from home; the infected men then transmit the virus to wives and other sex partners en route and in their place of origin [2] [4] [9] [12] [13]. Consistent with this pattern, there is growing evidence that migrant and other mobile individuals may act as bridge populations who spread the infections from high to low-risk populations and from urban to rural areas [14]-[17].

Ghana, one of the growing economies in sub-Saharan Africa, is currently experiencing an uncontrolled increase in number of migrants due to its large gold reserves and recently the discovery of oil in commercial quantities. Ghana operates the world's largest gold mine in Obuasi, Tarkwa, Konongo, Prestea, Akwatia and Mpohor Wassa East. Largely because of Ghana's economic reforms over the last 10 years, there is an influx of large number of migrants from other countries such as South Africa, Kenya, Zimbabwe, Nigeria, Mali, Burkina Faso, Senegal, Cameroon, Gambia, Senegal, China, Europe and the USA who are mostly male, young, and poor have migrated to the mining areas in search of work [1]-[3] [5] [6] [8] [9] [12] [14] [17]. Unsubstantiated data suggest that as many as 1.5 million migrants are living in Ghana, particularly in the mining areas. Due to high rates of unprotected sex and drug use behaviours, Ghana's "floating population" of migrant workers are at risk for HIV/STIs and may play a critical role in the spread of HIV and syphilis in Ghana as has been observed in other countries [18]-[22]. As mobility has increased and the economy has grown, anecdotal reports indicate that commercial sex industry has boomed and HIV and syphilis rates have risen. Separated from home and working long hours in difficult conditions, male migrants may patronize female sex workers, increasing their risk of HIV and helping to fuel epidemics of HIV and syphilis. Within Ghana, there has been little or no information of male or female migrant workers' sexual behaviours and how these may facilitate risks of acquiring and transmitting HIV and syphilis in the country. Recent studies suggest that premarital and extramarital sexual relationships are common among migrant men and women [23]-[25]. Numerous studies also suggest that migrant men living predominantly in male settings and groups [1]-[4] [26] [27] and those who drink alcohol are substantially more likely to engage in risky behaviours such as unprotected sex [28]. Other contributing factors to HIV and syphilis vulnerability include low knowledge of HIV and syphilis transmissions and prevention [9] [10] [29], availability of cheap sex, singlehood, low perceived vulnerability to HIV and syphilis [9] [10] [28], and existing cultures of risky sexual behaviours [30]. The uptake of safer sex measures and patterns of health service in these migrant populations is unknown. Also the demographic profile of these young and frequently single migrants and their lack of experience of the Ghana Health System may place these new migrant population or communities at higher risk of sexual ill health and reproductive morbidity compared with the general population. The prevalence of HIV in Ghana is 1.37\% (Ghana National AIDS Control Programme, Ghana Health Service 2012 Sentinel Survey); whereas the reported sero-prevalence of Treponema pallidum, the causative agent of syphilis is $0.6 \%$ (Ghana National AIDS Control Programme, Ghana Health Service 2012 Sentinel Survey). This work determined the prevalence of HIV and syphilis among migrant workers in Konongo, Ghana. In this study, we also examined the association of HIV with various suggested risk factors for its transmission.

\section{Materials and Methods}

\subsection{Study Site Description}

The study is a cross sectional study carried out between the months of January 2013 to December 2013 among 
migrant workers at Nyaboo, Patriensa, Obenemase and Konogo-Odumase in the Konongo Municipality, small scale illegal mining centres within the Asante Akim District in the Ashanti region of Ghana. Ghana is divided into ten (10) administrative regions, subdivided into a total of 216 districts or municipalities. However, in addition to the four [4] mining centres, there are several legally registered mining centres and other illegal small scale mining centres in Konongo whose activities have resulted in the pollution of all the rivers thereby threatening the health of the people in the area. The study site was chosen because Konongo is the common destination for migrant workers and because they represent the two common types of migration (long term, more than 6 months stay and short term, less than 6 months). In addition, the site is most active, and has one of the largest reserve of mineral deposits. The population of the Municipality is estimated at 41,238 using the 2000 Housing and Population Census as a base and applying a 4\% annual growth rate (National Population and Housing Survey, 2000). The predominant occupation in the Municipality is subsistence agriculture; however, with the upsurge of the illegal mining activities in the Municipality, subsistence agriculture is no longer the predominant occupation.

\subsection{Study Population}

Subjects for this study were both male and female migrants. The study was proposed to the entire population of each migrant settling community or group after an explanation of the purpose of the study at a meeting organized for that purpose in each of these groups. They were informed that the study was confidential and that the information provided by the migrants would not affect their immigration status. A total of 600 migrants were invited and recruited for the study, but only 164 migrants consented and were enrolled in the research. Written informed consent was obtained from each consenting participant and the information regarding the protocol and informed consent was presented at the appropriate literacy level. The study was conducted in a confidential manner and random unique study-generated numbers were employed to identify the participants. The Ethical and Protocol Review Committee of the University of Ghana Medical School, Accra, Ghana, approved the study.

\subsection{Questionnaire}

All the 164 consenting participants completed a structured questionnaire assessing socio-demographic characteristics, sexual and drug histories, and a risk factor profile for the infections under investigation. Physical examination was done to evaluate the general health condition of each participant at the study sites.

\subsection{Sample Collection and Serological Analysis}

Blood (10 ml) samples were collected from each of the 164 consenting participants in plain tubes. Samples were centrifuged and the serum kept at $-20^{\circ} \mathrm{C}$ until analysed. Sera were tested at the Public Health Reference Laboratories, Korle Bu, Accra, Ghana for the presence of antibodies to HIV 1 and 2 (ELISA and Western Blot; Abbot and Cambridge Biotech, respectively), and antibodies to T. pallidum [T. pallidum haemagglutination assay (TPHA) test; Serodia Fujirebio] in accordance with the respective manufacturer's instructions. Repeatedly reactive specimens by ELISA were assayed by Western blotting for confirmation.

\subsection{Statistical Analysis}

The Statistical Analysis Software (SAS Institute, Cary, NC, USA) version 9.1 was used to complete all data analyses. For each generally accepted risk factor for HIV infection, the odds ratio (OR) and the 95\% confidence interval (95\% CI) were calculated to assess associations with socio-demographic and behavioural variables in univariate analysis. A P-value of $<0.05$ was considered significant. Independent associations were evaluated by calculating the adjusted OR by multivariate analysis for the socio-demographic behavioural variables found to be significant in the univariate analysis.

\section{Results}

\subsection{Study Population}

A total of 164 migrants who worked in gold mining centres in Konongo participated in the study (27.3\% of the total of 600 eligible migrants in the four sites studied). The migrants consisted of 156 Ghanaian citizens and 8 
non-Ghanaian citizens. Of the 8 non-Ghanaian citizens who worked in the gold mining centres, three (3) were from Cote D'Iviore, two (2) from Togo, two (2) from Burkina Faso and one (1) from Niger. Of the 164 consenting participants, 114 (69.5\%) were males (median age was 29 years; range 18 - 62), and 50 (30.5\%) were females (median age was 27 years; range 19 - 54). The participation for the study at the four studied sites ranged from $17.5 \%$ (Nyaboo) to $34.1 \%$ (Patriensa). All the 164 consenting migrants who worked in the gold mining centres completed interviews and blood testing, and the results herein presented are from these 164 migrants. Data from male and female participants were combined because only 50 out of the 164 consenting participants were females. All the consenting migrants who worked in the gold mining centres were occupationally exposed to the adverse working conditions at the gold mining sites. They engaged in the gold mining activities for various reasons, the most common being the lack of jobs (55.5\%), followed by relatively low income (37.2\%) and introduction by friends and relatives (7.3\%).

Of the 164 migrants who worked in the gold mining centres, 33.5\% (55 out of 164) had been working in the same gold mining setting for more than 60 months whilst 66.5\% (109 out of 164) had been working in the same gold mining setting for less than 60 months. The most common sign by far on physical examination was pallor in 73.2\% (120 out of 164) of the participating migrants, followed by skin lesions (superficial fungal and bacterial infections, and scabies) in 48.8\% (80 out of 164) and hypertension (blood pressure $\geq 140 / 90 \mathrm{~mm} \mathrm{Hg}$ ) in 30.5\% (50 out of 164). The most common symptom was loss of appetite in $60.4 \%$ of the participating migrants, followed by skin rashes in $20.7 \%$ (34 out of 164).

\subsection{Prevalence of HIV and Syphilis}

The overall prevalence of HIV-1 was 6.7\% (11 out of 164), with none testing positive for HIV-2. Of the persons who tested positive for HIV-1, 54.5\% (6 out of 11 ) were females, whilst $45.5 \%$ (5 of 11 ) were males. There was no significant difference between them, $\mathrm{P}>0.05$. Of the eight (8) non-Ghanaian citizens who participated in the study, two (2) were seropositive for HIV-1.

Syphilis infection among the study participants who worked in the gold mining centres was $3.7 \%$ (6 out of 164). Of the participants who tested positive for syphilis, $83.3 \%$ (5 out of 6 ) were males, whereas $16.7 \%$ ( 1 of 6 ) were females. There was no significant difference between them, $\mathrm{P}>0.05$. None of the 8 non-Ghanaian citizens were seropositive for syphilis antibodies.

Table 1 shows the ORs and the corresponding 95\% CIs according to age for HIV and syphilis seropositivity among the study participants who worked in the gold mining centres. HIV seropositivity (7 out of 11) was highest in migrants aged 20 - 29 years. However, compared with the 20 - 29 year group, migrants aged 30 - 39 years, who worked in the gold mining centre, were associated with a decreased (OR 0.46; 95\% CI 0.09 - 2.38) HIV seropositivity. Conversely, the greatest risk of syphilis seropositivity was associated with those in the upper age group (above 50 years) and, to a lesser extent, those in the middle age group (40 - 49 years) followed by those in the 30 - 39 years age group. There were also no co-infections of HIV and syphilis among participants.

Table 2 shows the ORs and corresponding 95\% CIs according to duration of stay among the migrants. Shortterm migrants ( $<6$ months), accounting for $25.61 \%$ of the study participants had a decreased risk (OR 0.59; 95\% CI 0.12 - 2.83) of HIV infection and were at an increased risk (OR 1.39; 95\% CI 0.24 - 7.69) of syphilis infection as compared with long-term ( $>6$ months) migrants who worked in the gold mining centres.

\subsection{Risk Factors}

Table 3 shows the ORs for HIV and syphilis seropositivity and the corresponding 95\% CIs according to the

Table 1. Age distribution, HIV and syphilis seropositivity among participants.

\begin{tabular}{|c|c|c|c|c|c|c|c|c|c|c|c|}
\hline \multirow{2}{*}{\multicolumn{2}{|c|}{ Characteristic }} & \multicolumn{2}{|c|}{ HIV Status } & \multirow{2}{*}{ OR } & \multirow{2}{*}{$95 \%$ CI } & \multirow{2}{*}{ P-Value } & \multicolumn{2}{|c|}{ Syphilis Status } & \multirow{2}{*}{ OR } & \multirow{2}{*}{$95 \%$ CI } & \multirow{2}{*}{ P-Value } \\
\hline & & Pos (11) & Neg (153) & & & & Pos (6) & Neg (158) & & & \\
\hline \multirow{5}{*}{ Age } & $<20$ & 0 & 8 & - & - & 0.51 & 0 & 8 & - & - & 0.82 \\
\hline & $20-29$ & 7 & 74 & * & & & 2 & 79 & * & $0.24-12.50$ & 0.20 \\
\hline & $30-39$ & 2 & 45 & 0.46 & $0.09-2.38$ & 0.29 & 2 & 45 & 1.75 & $0.02-3.45$ & 0.47 \\
\hline & $40-49$ & 2 & 19 & 1.11 & $0.21-5.56$ & 0.59 & 1 & 20 & 1.96 & $0.17-25.00$ & 0.50 \\
\hline & $\geq 50$ & 0 & 7 & - & - & 0.55 & 1 & 6 & 6.67 & $0.52-100.0$ & 0.22 \\
\hline
\end{tabular}

\footnotetext{
*: baseline for OR calculations, -: non-estimable.
} 
Table 2. Duration of stay in months among the study participants compared with HIV and syphilis seropositiity.

\begin{tabular}{|c|c|c|c|c|c|c|c|c|c|c|c|}
\hline & & \multicolumn{2}{|c|}{ HIV Status } & \multirow{2}{*}{ OR } & \multirow{2}{*}{$95 \%$ CI } & \multirow{2}{*}{ P-Value } & \multicolumn{2}{|c|}{ Syphilis status } & \multirow{2}{*}{ OR } & \multirow{2}{*}{$95 \%$ CI } & \multirow{2}{*}{ P-Value } \\
\hline & & Pos (11) & Neg (153) & & & & Pos (6) & Neg (158) & & & \\
\hline $\begin{array}{c}\text { Duration } \\
\text { (months) }\end{array}$ & $\begin{array}{l}\text { Short term } \\
\text { Long term }\end{array}$ & $\begin{array}{l}2 \\
9\end{array}$ & $\begin{array}{c}42 \\
111\end{array}$ & $\begin{array}{c}0.59 \\
*\end{array}$ & $0.12-2.83$ & 0.39 & $\begin{array}{l}2 \\
4\end{array}$ & $\begin{array}{c}42 \\
116\end{array}$ & $\begin{array}{c}1.39 \\
*\end{array}$ & $0.24-7.69$ & 0.51 \\
\hline
\end{tabular}

*: baseline for OR calculations, -: non-estimable.

Table 3. Summary of socio-demographic characteristics, HIV and Syphilis seropositivity among the study participants.

\begin{tabular}{|c|c|c|c|c|c|c|c|c|c|c|c|}
\hline & & \multicolumn{2}{|c|}{ HIV Status } & \multirow[b]{2}{*}{ OR } & \multirow{2}{*}{$95 \%$ CI } & \multirow{2}{*}{ P-Value } & \multicolumn{2}{|c|}{ Syphilis Status } & \multirow{2}{*}{ OR } & \multirow{2}{*}{$95 \%$ CI } & \multirow[b]{2}{*}{ P-Valu } \\
\hline & & $\begin{array}{l}\text { Pos } \\
\text { (11) }\end{array}$ & $\begin{array}{l}\text { Neg } \\
\text { (153) }\end{array}$ & & & & Pos (6) & Neg (158) & & & \\
\hline \multirow{2}{*}{ Gender } & Male & 5 & 109 & * & & & 5 & 109 & * & & \\
\hline & Female & 6 & 44 & 2.94 & $0.86-10.0$ & 0.08 & 1 & 49 & 0.44 & $0.05-3.84$ & 0.41 \\
\hline \multirow{4}{*}{ Education } & Illiterate & 2 & 28 & * & & & 2 & 28 & * & & \\
\hline & Basic & 7 & 102 & 0.96 & $0.19-4.76$ & 0.62 & 3 & 106 & 0.39 & $0.06-2.50$ & 0.29 \\
\hline & Secondary & 2 & 22 & 1.28 & $0.17-10.0$ & 0.61 & 1 & 23 & 0.61 & $0.05-7.14$ & 0.59 \\
\hline & Tertiary & 0 & 1 & - & & 0.94 & 0 & 1 & - & - & 0.94 \\
\hline \multirow{2}{*}{$\begin{array}{c}\text { Marital } \\
\text { Status }\end{array}$} & Married & 1 & 77 & * & & & 4 & 73 & * & & \\
\hline & Unmarried & 10 & 76 & 10.13 & $1.2-81.09$ & 0.007 & 2 & 85 & 0.43 & $0.08-2.41$ & 0.28 \\
\hline \multirow{3}{*}{ Religion } & Christian & 11 & 126 & * & & & 3 & 134 & $*$ & & \\
\hline & Muslim & 0 & 21 & - & - & 0.19 & 2 & 19 & 4.76 & $0.73-33.33$ & 0.13 \\
\hline & Other & 0 & 6 & - & - & 0.61 & 1 & 5 & 9.09 & $0.78-100.0$ & 0.16 \\
\hline \multirow{2}{*}{ Nationality } & Ghanaian & 9 & 147 & * & & & 6 & 150 & * & & \\
\hline & Non-Ghanaian & 2 & 6 & 5.56 & $0.96-33.33$ & 0.09 & 0 & 8 & - & - & 0.74 \\
\hline
\end{tabular}

*: baseline for OR calculations, -: non-estimable.

socio-demographic characteristics of the migrants who worked in gold mining centres. Female migrants who worked in the gold mining centres had a 2.94-fold (95\% CI 0.86 - 10.0) of HIV infection and a decreased risk (OR 0.44; 95\% CI 0.05 - 3.84) of syphilis infection as compared with male migrants who worked in the gold mining centres. Migrants who worked in the gold mining centres and had attained a formal secondary level education, accounting for $14.63 \%$ of study participants, were at an increased risk (OR 1.28; 95\% CI 0.17 - 10.0) of HIV infection as compared with illiterate migrants and those who attained basic and tertiary levels of education. Unmarried migrants who worked in the gold mining centres accounting for $52.44 \%$ of the study participants, had 10.13-fold (95\% CI 1.2 - 81.09) higher risk of HIV infection as compared with married migrants. Compared to Christian migrants who worked in the gold mining centres, the greatest risk of syphilis seropositivity was associated with migrants who practiced other religions (OR 9.09; 95\% CI 0.78 - 100.0) and Muslims (OR 4.76; 95\% CI 0.73 - 33.33) who worked in gold mining centres. However, all migrants who were seropositive to HIV were Christians (Table 3). Non-Ghanaians citizens who worked in the gold mining centres, accounting for 4.89\% of the study participants, were at an increased risk (OR 5.26; 95\% CI 0.85 - 33.33) of HIV infection as compared with Ghanaian citizens who worked in the gold mining centres.

Table 4 shows the ORs for HIV and syphilis seropositivity and corresponding 95\% CI according to behavioral characteristics of the study participants. Migrants who worked in the gold mining centres and with concurrent sexual partnerships had 2.16-fold (95\% CI 0.38 - 12.12) higher risk of syphilis infection as compared with those who do not have concurrent sexual partners. Migrants who worked in the gold mining centres reporting a previous history of drug use, alcohol use, STDs, tattoos, and blood transfusion were all associated with increased HIV seropositivity as compared with migrants reporting no such previous history (Table 4). Migrants who worked in the gold mining centres reporting no knowledge of HIV and syphilis had a 1.6-fold (95\% CI 0.18 13.96) increased risk of HIV seropositivity. 
Table 4. Odds ratios and association between HIV, syphilis and selected risk factors.

\begin{tabular}{|c|c|c|c|c|c|c|c|c|c|c|c|}
\hline & & \multicolumn{2}{|c|}{ HIV Status } & \multirow[b]{2}{*}{ OR } & \multirow[b]{2}{*}{$95 \%$ CI } & \multirow[b]{2}{*}{ P-Value } & \multicolumn{2}{|c|}{ Syphilis Status } & \multirow[b]{2}{*}{ OR } & \multirow[b]{2}{*}{$95 \%$ CI } & \multirow[b]{2}{*}{ P-Value } \\
\hline & & Pos (11) & $\begin{array}{l}\text { Neg } \\
\text { (153) }\end{array}$ & & & & Pos (6) & Neg (158) & & & \\
\hline \multirow{2}{*}{ Condom Use } & No & 11 & 135 & - & - & 0.27 & 4 & 142 & 0.23 & $0.04-1.34$ & 0.13 \\
\hline & Yes & 0 & 18 & * & - & & 2 & 16 & ${ }^{*}$ & & \\
\hline \multirow{2}{*}{$\begin{array}{c}\text { Concurrent sexual } \\
\text { partners }\end{array}$} & No & 6 & 78 & $*$ & & & 2 & 82 & * & & \\
\hline & Yes & 5 & 75 & 0.87 & $0.25-2.96$ & 0.53 & 4 & 76 & 2.16 & $0.38-12.12$ & 0.32 \\
\hline \multirow{2}{*}{ Drug use } & No & 10 & 149 & & & & 6 & 153 & $*$ & & \\
\hline & Yes & 1 & 4 & 3.76 & $0.38-36.53$ & 0.30 & 0 & 5 & - & - & 0.83 \\
\hline \multirow{2}{*}{ Alcohol use } & No & 6 & 104 & * & & & 4 & 106 & * & & \\
\hline & Yes & 5 & 49 & 1.77 & $0.52-6.08$ & 0.27 & 2 & 52 & 1.02 & $0.18-5.75$ & 0.65 \\
\hline \multirow{2}{*}{ History of STI } & No & 8 & 123 & * & & & 4 & 127 & * & & \\
\hline & Yes & 3 & 30 & 1.54 & $0.39-6.15$ & 0.39 & 2 & 31 & 2.05 & $0.36-11.70$ & 0.35 \\
\hline \multirow{2}{*}{ Payment for sex } & No & 11 & 151 & * & & & 6 & 156 & * & & \\
\hline & Yes & 0 & 2 & - & & 0.87 & 0 & 2 & - & - & 0.93 \\
\hline \multirow{2}{*}{$\begin{array}{l}\text { Knowledge of } \\
\text { HIV/Syphilis }\end{array}$} & No & 1 & 9 & 1.60 & $0.18-13.92$ & 0.51 & 0 & 19 & - & - & 0.47 \\
\hline & Yes & 10 & 144 & * & & & 6 & 139 & $*$ & & \\
\hline Tattoos or & No & 9 & 137 & * & & & 6 & 140 & ref & & \\
\hline Body marks & Yes & 2 & 16 & 1.9 & $0.38-9.58$ & 0.35 & 0 & 18 & - & & 0.49 \\
\hline Blood & No & 10 & 147 & * & & & 5 & 152 & * & & \\
\hline transfusion & Yes & 1 & 6 & 2.45 & $0.27-22.37$ & 0.39 & 1 & 6 & 5.07 & $0.51-50.37$ & 0.23 \\
\hline
\end{tabular}

*: baseline for OR calculations, -: non-estimable.

\section{Discussion}

Migration (long term or short term) is a major contributor to the HIV/AIDS epidemics and syphilis infection as it increases the number of sexual partnerships as well as contacts with high-risk groups such as commercial sex workers. Growing evidence suggest that migrants and other mobile individuals act as bridge populations who spread the infections from high-risk to low-risk populations and regions as well as urban to rural areas [14]-[17]. Subsequently, knowledge of the prevalence, risk factors and distribution of HIV/AIDS, blood-borne viruses and STDs in different parts of the world, particularly in Africa, is important for the planning of preventive measures and the development of vaccination programmes. Furthermore, the comparison of their prevalence and the risk factors among migrant workers and the general population in the same geographical area is important to provide a basis for action, and changes in public health policy, education and clinical practice. The purpose of this study was to determine correlates of HIV and syphilis infections among migrants (Ghanaians and non-Ghanaians) who work in gold mining centres in Konongo, Ghana.

To our knowledge, this is the first study in Ghana reporting correlates of HIV and syphilis infections in migrants who work in gold mining centres and demonstrates the high prevalence of and the considerable potential for the transmission of HIV and syphilis infections in gold mining communities in Ghana. Although there is no report from the Ministry of Health and The Ghana AIDS Commission, Accra, Ghana on the HIV and syphilis infections among migrants working or who worked in gold mining centres, this study found very high overall prevalence rate of HIV (6.7\%) as compared to the prevalence rate $(1.37 \%)$ of HIV in the general population (Ghana National AIDS Control Programme, Ghana Health Service 2012 Sentinel Survey). However, the seroprevalence of syphilis (3.7\%) among migrants working or who worked in the goal mining centres was higher (0.6\%) compared to that previously reported in the general population (Ghana National AIDS Control Programme, Ghana Health Service 2012 Sentinel Survey). The results of the present study support previous reports that migrants represent a high-risk group for HIV and syphilis infections [1]-[3] [5] [6] [8] [9] [12] [14] [17]. However, further studies with a large number of migrants working in the gold mining centres will be necessary to draw a definitive conclusion

The risk of HIV and syphilis infections did not correlate with increasing age; however, all the study participants 
who were seropositive to HIV-1 (11 out of 164; Table 1) infection were in the 20 - 49 years aged group. The finding of higher HIV antibody prevalence in migrants aged 20 - 49 years who work in the gold mining centres in Konongo, Ghana is consistent with literature, and is widely attributable to work-related behaviours, life styles and attitudes practiced on the mining settings, although transmission of HIV has also been documented among migrants outside the gold mining setting [1] [2] [31]-[33]. The overall sero-prevalence of HIV (6.7\%) and syphilis (3.7) infections among migrants who worked in the gold mining centres in Ghana is higher than the results of similar studies in migrants who worked in gold mining workers in China (HIV, 0.78\%; syphilis, 1.8\%) [38] but comprable to the reported HIV sero-prevalence of $6.0 \%$ in migrants who worked in gold mining centres in Tanzania [33]. However, the sero-prevalence of syphilis in the migrants who worked in gold mining centres in Tanzanian is higher (9.0\%) [33] than those in Ghana (3.7\%). The increased sero-prevalence of HIV (6.7\%) and syphilis (3.7\%) in migrants who worked in gold mining centres in Ghana suggests that HIV and syphilis infections may be widespread in gold mining workers in the country and therefore reasonable to speculate that HIV and syphilis may circulate in the general population in mining communities.

Another finding of interest reported herein in our study is that there was no association between seropositivity of HIV and syphilis infections among the study participants who had been working in the same gold mining centres for more than 6 months (long-term); although a greater proportion of long-term migrants were seropositive to HIV (9 out of 11; Table 2) and syphilis (4 out of 6; Table 2) as compared to those who had been working in the same gold mining centres for less than 6 months (short-term). The reason(s) for this disparity cannot be discerned from our study. However, it is likely due to the relatively small population group of migrants who participated in the study; and that it is also probable that the majority of the eligible migrants who may have been at higher risk of HIV or syphilis behaviours that may lead to detection declined to participate despite re-assurance of confidentiality and no change in their immigration status. Further studies need to be done to define the high prevalence of HIV, syphilis infections and other STIs associated with short-term and long-term migrants who worked or have been working in mining communities and the impact of HIV, syphilis infections and other STIs on the local population in the mining communities.

HIV seroprevalence rate was particularly high in unmarried migrants who work in the gold mining centres as compared with married migrants (Table 3). The finding of higher HIV seropositivity in unmarried migrants is consistent with literature, and is widely attributable to separation from partners and family, peer pressure, alcohol and drug use, low perceived vulnerability to HIV infection, limited access to health care, low level of education, loneliness, insecurity and freedom from social norms [1]-[6] [36] [37]. The presence of HIV seropositivity among unmarried migrants who work in gold mining centres in Konongo suggests that migrants may be a bridge or core population in the spread of HIV infection in gold mining centres in Ghana and may signify recent introduction of HIV into these gold mining centres. This is necessary because several reports indicate that migrants are often considered bridge or core populations for acquiring and transmitting HIV and STIs from high-risk groups to low-risk groups [1] [38] [39]. There is therefore the need to investigate migrants working in other gold mining centres and the population around the mining communities to ascertain whether there had been any earlier HIV and syphilis infections within the mining communities. There is also the need for further studies to define the clinical and epidemiological importance and pathogenesis of HIV and syphilis infections in the migrant population and within the community.

There was an association between HIV and syphilis infections and a previous history of drug use, alcohol use, STI, tattoos, blood transfusion and knowledge of HIV/syphilis Table 4). The results of our study are consistent with current literature suggestive that mining communities are high risk for HIV and STI transmission, largely due to the temporary nature of the work and associated disruptive social ties [1]-[6] [36].

Of interest, all migrants who worked in the gold mining centres studied and were seropositive to HIV and syphilis infections had no previous history of condoms use (Table 4). Our results are in agreement with others conducted elsewhere which suggest that non-regular and inconsistent use of condoms may increase the transmission of HIV and STIs [40]-[42]. Based on our results and coupled with the proliferation of drinking bars and other recreational facilities in Konongo, and the influx of migrants, there is the need to provide general HIV/STI education to all the sectors of the community. This is necessary because we found low level of condom use among the study participants.

The small sample size, inability to collect information on sexual practices prior to migration, under-reporting of sexual activity, alcohol use and other risk behaviours as a result of the face-to-face interview, failure to explore or define the effects of separation from families and cultural factors in predicting risk behaviours of mi- 
grants, may be the limitations of this study. The detection and prevalence of HIV and syphilis infections in migrants who work in gold mining centres in Konongo may not reflect the situation among migrants in other gold mining centres in the country. This is because of district and regional differences in terms of demographics, economic conditions, and illicit drug availability and use. Further studies need to be done to define clearly the natural history of HIV and syphilis infections and transmission in Ghana in order to effectively control and prevent the spread HIV and syphilis among migrants and mining communities.

The results reported herein have significant implications for public health officials, clinicians, officials at the Ghana Health Service, Ghana AIDS Commission and the Ministry of Health and suggest urgent need for the introduction of policies to prevent the transmission of HIV on mining centres and the general population. These policy strategies must include increasing education of persons who work in mining centres and communities around the mining centres about HIV, STIs testing, prevention and control. The implementation of a HIV, STI infections prevention programme in mining centres and mining communities in Ghana should be seen as an opportunity to improve the health status of the infected persons who work in the mines and the residents in the mining communities and to prevent further transmission of HIV, STIs within and without the mining settings.

\section{Conclusion}

In conclusion, our results suggest that migrants who work in gold mining centres are at increased potential risk of HIV and syphilis infections. The high prevalence of HIV and syphilis infections found in migrants who work in the gold mining centres in Konongo, Ghana, suggests the urgent need for the introduction of some of the range of effective preventive strategies employed in gold mining centres elsewhere.

\section{Acknowledgements}

This study was supported with funds from the University of Ghana-Brown University Research Partnership. We are indebted to Mr. Edmund Nartey, Mubarak Abdul-Rahman, Jones Opoku Mensah and Felix Solvor. We are also grateful to all the Opinion Leaders in the Mining centres in Konongo and all the migrant workers.

\section{References}

[1] Brummer, D. (2002) Labour Migration and HIV/AIDS in Southern Africa. International Organisation for Migration Regional Office for Southern Africa.

www.aidsmark.org/ipc_en/pdf/sm/hr/mwmp/Labor\%20Migration\%20and\%20HIV-AIDS\%20in\%20Southern\%20Afric a.pdf

[2] Richens, J. (2006) Sexually Transmitted Infections and HIV among Travelers: A Review. Travel Medicine and Infectious Disease, 4, 184-195.

[3] Giami, A. and Le Bail, J. (2011) HIV Infection and STI in the Trans Population: A Critical Review. Revue d'Épidémiologie et de Santé Publique, 59, 259-268. http://dx.doi.org/10.1016/j.respe.2011.02.102

[4] Nahmias, S.B. and Nahmias, D. (2011) Society, Sex, STIs: Human Behavior and the Evolution of Sexually Transmitted Diseases and Their Agents. Annals of the New York Academy of Sciences, 1230, 59-83. http://dx.doi.org/10.1111/j.1749-6632.2011.06079.x

[5] Wolffers, I., Fernandez, I., Verghis, S. and Vink, M. (2002) Sexual Behavior and Vulnerability of Migrant Workers for HIV Infection. Culture, Health \& Sexuality, 4, 459-473. http://dx.doi.org/10.1080/13691050110143356

[6] Brockerhoff, M. and Biddlecom, A.F. (1999) Migration, Sexual Behavior and the Risk of HIV Infection in Kenya. International Migration Review, 33, 833-856. http://dx.doi.org/10.2307/2547354

[7] Lurie, M., Harrison, A., Wilkinson, D. and Abdool-Karim, S.S. (1997) Circular Migration and Sexual Networking in Rural KwaZulu/Natal: Implications for the Spread of HIV and Other Sexually Transmitted Diseases. Health Transition Review, 7, 17-27.

[8] Owoaje, E.T., Adebiyi, A.O. and Adebayo, M.A. (2011) Sexual Risk Behaviours and HIV Knowledge of Migrant Farm Workers in a Rural Community in Nigeria. African Journal of Medicine and Medical Sciences, 40, 75-84.

[9] Mantell, J.E., Kelvin, E.A., Sun, X., Zhou, J., Exner, T.M., Hoffman, S., Zhou, F., Sandfort, T.G. and Leu, C.S. (2011) HIV/STI Risk by Migrant Status among Workers in an Urban High-End Entertainment Centre in Eastern China. Health Education Research, 26, 283-295. http://dx.doi.org/10.1093/her/cyr002

[10] Setiawan, I.M. and Patten, J.H. (2010) The Organization of STI/HIV Risk-Taking among Long-Line Fishermen in Bali, Indonesia. International Maritime Health, 62, 201-208. 
[11] Grayman, J.H., Nhan, D.T., Huong, P.T., Jenkins, R.A., Carey, J.W., West, G.R. and Minh, T.T. (2005) Factors Associated with HIV Testing, Condom Use and Sexually Transmitted Infections among Female Sex Workers in Nha Trang, Vietnam. AIDS and Behavior, 9, 41-51. http://dx.doi.org/10.1007/s10461-005-1680-5

[12] Pison, G., Guenno, B.L., Lagarde, E. and Seck, C. (1993) Seasonal Migration: A Risk Factor for HIV Infection in Rural Senegal. Journal of Acquired Immune Deficiency Syndromes, 6, 196-200.

[13] Gangakhedkar, R.R., Bentley, M., Divekar, A., Gadkari, D., Monhendal, S.M. and Shepherd, M.E. (1997) Spread of HIV Infection in Married Monogamous Women in India. JAMA, 278, 2090-2092. http://dx.doi.org/10.1001/jama.1997.03550230066039

[14] Morris, M., Podhista, C., Wawer, M.I. and Handrock, M.S. (1996) Bridge Populations in the Spread of HIV/AIDS in Thailand. AIDS, 10, 1265-1271. http://dx.doi.org/10.1001/jama.1997.03550230066039

[15] Entz, A.T., Ruffolon, V.P., Chinveschakitvanich, V., Soskoline, V. and van Griensven, G.J.P. (2000) HIV-1 Prevalence, HIV-1 Subtypes and Risk Factors among Fishermen in the Gulf of Thailand and the Andaman Sea. AIDS, 14, 1027-1034. http://dx.doi.org/10.1097/00002030-200005260-00015

[16] Chandrasekaran, P., Dallabetta, G., Loo, V., Rao, S., Gayle, H. and Alexander, A. (2005) Containing HIV/AIDS in India: The Unfinished Agenda. The Lancet Infectious Diseases, 6, 508-521. http://dx.doi.org/10.1016/S1473-3099(06)70551-5

[17] Decosas, J., Kane, F., Anarfi, J.K., Sodji, K.D.R. and Wagner, H.U. (1995) Migration and AIDS. The Lancet, 346, 826828. http://dx.doi.org/10.1016/S0140-6736(95)91631-8

[18] Pezzoli, M.C., Hamad, I.E., Scarcella, C., Vassallo, F., Speziani, F., Cristini, G., Scolari, C., Suligol, B., Luzi, A.M., Bernasconi, D., Litchner, M., Cassara, G., Manca, N., Carosi, G., Castelli, F. and Cassara, G., The PRISHMA Study Group (2009) HIV Infection among Illegal Migrants, Italy, 2004-2007. Emerging Infectious Diseases, 15, $1802-1804$. http://dx.doi.org/10.3201/eid1511.090908

[19] Gil, V.E., Wang, M.S. and Anderson, A.F. (1996) Prostitutes, Prostitution and STD/HIV Transmission in Mainland China. Social Science Medicine, 42, 141-152. http://dx.doi.org/10.1016/0277-9536(95)00064-X

[20] Fosados, R., Caballero-Hoyos, R., Torres-López, T. and Valente, T.W. (2006) Condom Use and Migration in a Sample of Mexican Migrants: Potential for HIV/STI Transmission. Salud Pública de México, 48, 57-61. http://dx.doi.org/10.1590/S0036-36342006000100009

[21] Burns, F.M., Evans, A.R., Mercer, C.H., Parutis, V., Gerry, C.J., Mole, R.C.M., French, R.S., Imri, J. and Hart, G.J. (2011) Sexual and HIV Risk Behavior in Central and Eastern European Migrants in London. Sexually Transmitted Infections, 87, 318-324. http://dx.doi.org/10.1136/sti.2010.047209

[22] Memish, Z.A. and Osoba, A.O. (2006) International Travel and Sexually Transmitted Disease. Travel Medicine and Infectious Disease, 4, 86-93. http://dx.doi.org/10.1016/j.tmaid.2005.01.003

[23] Halli, S.S., Blanchard, J., Satihal, D.G. and Moses, S. (2007) Migration and HIV Transmission in Rural South India: An Ethnographic Study. Culture, Health \& Sexuality, 9, 85-94. http://dx.doi.org/10.1080/13691050600963898

[24] Silitonga, N., Davies, S.C., Kaldor, J., Wignall, S. and Okoseray, M. (2011) Prevalence over Time and Risk Factors for Sexually Transmissible Infections among Newly-Arrived Female Sex Workers in Timika, Indonesia. Sexual Health, 8, 61-64. http://dx.doi.org/10.1071/SH10038

[25] de Boer, I.M., Op de Coul1, E.L.M., Koedijk, F.D.H., van Veen, M.G., van Sighem, A.I. and van de Laar, M.J.W. (2006) HIV and Sexually Transmitted Infections in 2005. RIVM Report No. 441100024, RIVM, Bilthoven.

[26] Poudel, K.C., Jimba, M., Okumura, I., Sharma, M., Poudel-Tandukar, K. and Wakai, S. (2004) Migration in Far Western Nepal: A Time Bomb for a Future HIV/AIDS Epidemic? Tropical Doctor, 34, 30-31.

[27] Mishra, A. (2004) Risk of Sexually Transmitted Infections among Migrant Men: Findings from a Survey in India. Asian and Pacific Migration Journal, 13, 89-106.

[28] Kissinger, P., Liddon, N., Schmidt, N., Curtin, E., Salinas, O. and Narvaea, A. (2008) HIV/STI Risk Behaviors among Latino Migrant Workers in New Orleans Post-Hurricane Katrina Disaster. Sexually Transmitted Diseases, 35, 924-929. http://dx.doi.org/10.1097/OLQ.0b013e31817fa2cc

[29] Gupta, I. and Mitra, A. (1999) Knowledge of HIV/AIDS among Migrants in Delhi Slums. Journal of Health and Population in Developing Countries, 2, 26-32.

[30] Rao, A., Nag, M., Mishra, K. and Dey, A. (1994) Sexual Behavior Pattern of Truck Drivers and Their Helpers in Relation to Female Sex Workers. Indian Journal of Social Work, 55, 603-615.

[31] Deb, A.K., Deb, M., Saha, M.K., Chakraborty, S., Bhattachrya, S.K. and Detels, R. (2009) HIV Transmission Potential among Local and Migrant Factory Workers in Kolkata, India. AIDS and Behavior, 13, 928-938. http://dx.doi.org/10.1007/s10461-009-9542-1

[32] Gangnon, A.J., Merry, L., Bocking, J., Rosenberg, E. and Oxman-Martinez, J. (2010) South Asian Migrant Women 
and HIV/STIs: Knowledge, Attitudes and Practices and the Role of Sexual Power. Health and Place, 16, 10-15. http://dx.doi.org/10.1016/j.healthplace.2009.06.009

[33] Desmond, N., Allen, C.F., Cliff, S., Justine, B., Mzugu, J., Plummer, M.L., Watson-Jones, D. and Ross, D.A. (2005) A Topology of Groups at Risk of HIV, STI in a Gold Mining Town in North-Western Tanzania. Social Science Medicine, 60, 1739-1749. http://dx.doi.org/10.1016/j.socscimed.2004.08.027

[34] Zhang, G.L., Wong, M., Yi, P., Xu, J.J., Li, B.S., Ding, G.W., Ma, Y.L., Wang, H.B., Zheng, X.W., Wu, Z.L. and Wang, N. (2010) HIV-1 and STI Prevalence and Risk Factors of Miners in Mining Districts of Yunnan, China. Journal of Acquired Immune Deficiency Syndromes, 53, S54-S60. http://dx.doi.org/10.1097/QAI.0b013e3181c7d8d2

[35] Cliff, S., Anemona, A., Watson-Jones, D., Kanga, Z., Ndeki, L., Changalucha, J., Gavyole, A. and Ross, D.A. (2003) Variations of HIV and STI Prevalences within Communities Neighbouring New Goldmines in Tanzania: Importance for Intervention Design. Sexually Transmitted Infections, 79, 307-312. http://dx.doi.org/10.1136/sti.79.4.307

[36] UNAIDS (2001) Population Mobility and AIDS (UNAIDS Best Practice Collection). UNAIDS Technical Uptake, February, Geneva.

[37] Duke, M.R. and Gómez Carpinteiro, F.J. (2009) The Effects of Problem Drinking and Sexual Risk among Mexican Migrant Workers on Their Community of Origin. Human Organization, 68, 328.

[38] Anderson, A., Qingsi, Z., Hua, X. and Jianfeng, B. (2003) China's Floating Population and the Potential for HIV Transmission. AIDS Care, 15, 177-185; http://dx.doi.org/10.1080/0954012031000068326

[39] Lurie, M., William, B., Suma, K., Mkaya-Mwamburi, D., Garnett, G. and Storm, A. (2003) The Impact of Migration on HIV-Transmission in South Africa: A Study of Migrant and Nonmigrant Men and Their Partners. Sexually Transmitted Diseases, 30, 149-156. http://dx.doi.org/10.1097/00007435-200302000-00011

[40] WHO (2000) Effectiveness of Male Latex Condoms in Protecting against Pregnancy and Sexually Transmitted Infections. Fact Sheet No. 243, June 2000, Geneva.

[41] CDC (2002). www.cdc.gov/nchstp/od/condoms.pdf

[42] Foss, A.M., Watts, C.H., Vickerman, P. and Heise, L. (2004) Condoms and Prevention of HIV. BMJ, 329, $185-186$. http://dx.doi.org/10.1136/bmj.329.7459.185 
Scientific Research Publishing (SCIRP) is one of the largest Open Access journal publishers. It is currently publishing more than 200 open access, online, peer-reviewed journals covering a wide range of academic disciplines. SCIRP serves the worldwide academic communities and contributes to the progress and application of science with its publication.

Other selected journals from SCIRP are listed as below. Submit your manuscript to us via either submit@scirp.org or Online Submission Portal.
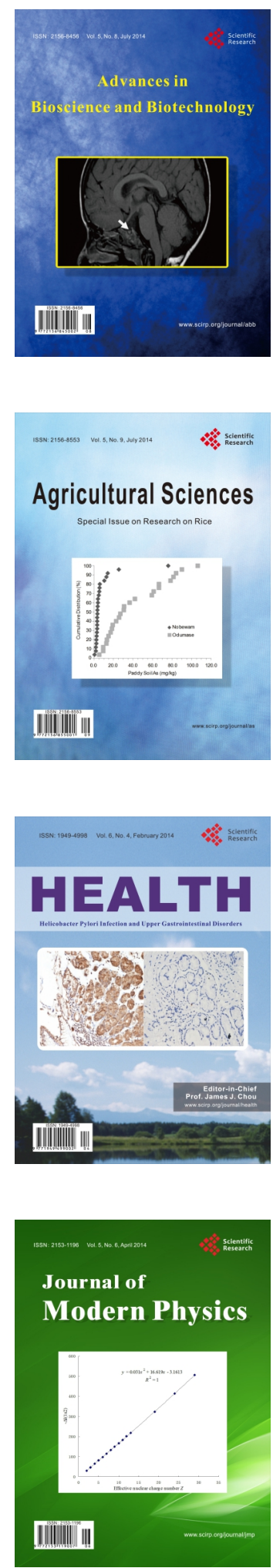
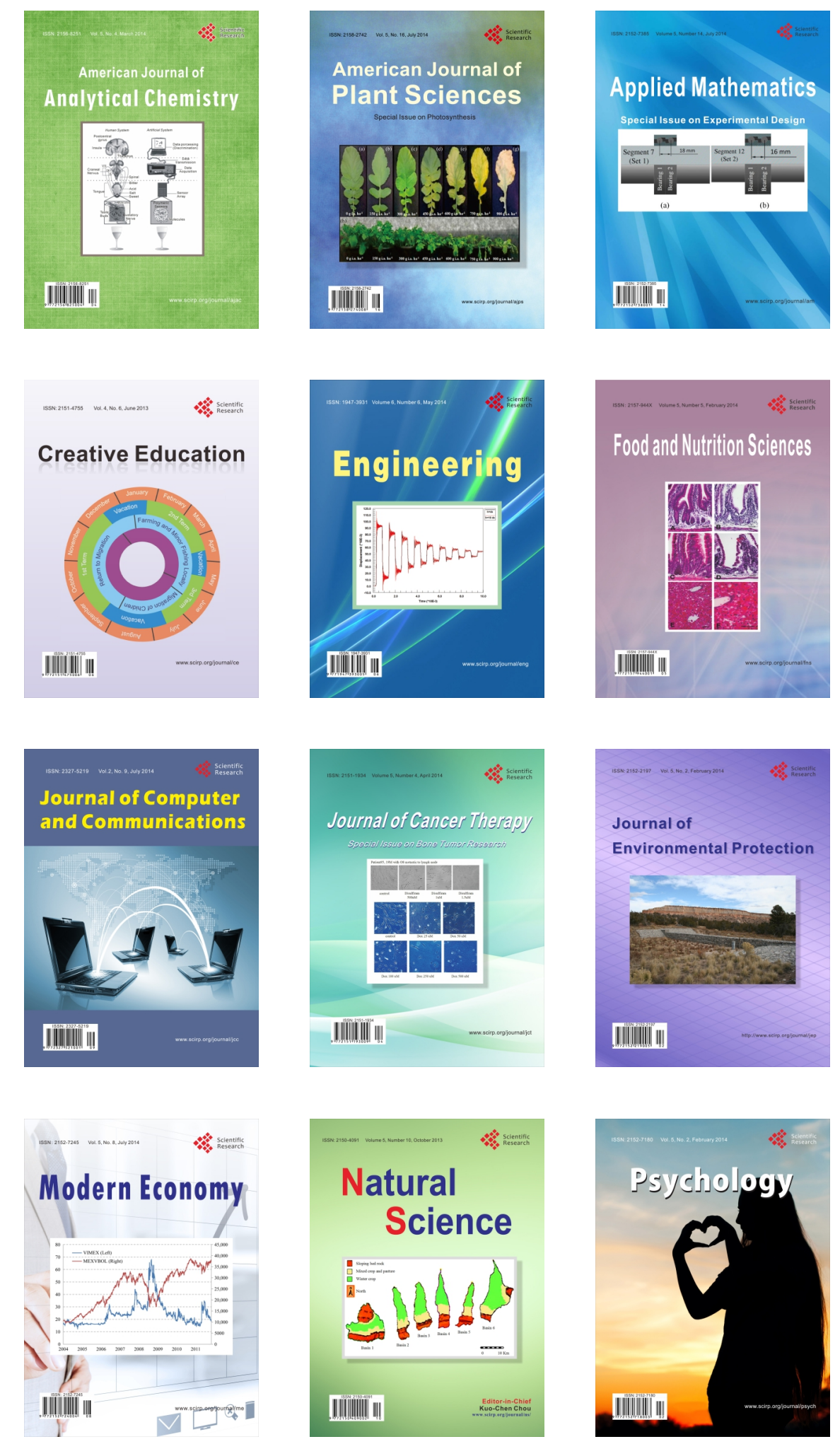